\title{
Knowledge and Attitude on Growth Monitoring and its Associated Factors among Mothers/Guardians of Children Less than Two Years in Areka Town, Southern Ethiopia, 2017
}

Beniam Daniel, Nardos Tesfaye, Ermias Mekonin, Awol Kassa, Kamil Mensur, Eshetu Zerihun, Ketema Deriba, Hiwot Tadesse and Tomas Yeheyis*

Department of Nursing, College of Medicine and Health Science, Arba Minch University, Arbaminch, Ethiopia

\begin{abstract}
Introduction: Growth Monitoring is the process of following and assessing the growth rate of a child in comparison to a standard by, periodic, frequent anthropometric measurements. Only a few have been said and researched about the maternal knowledge and attitude towards growth monitoring and its associated factors in Ethiopia as well globally. Therefore, this study was conducted to fill the observed gap.

Methods: Community based cross sectional study was conducted in Areka town, from June 2 to June 12, 2017 sample size was $369(p=0.53)$ after correction and proportional sample size allocation is used to allocate the sample to the 4 Kebeles and Systematic random sampling was used to select households. Data was collected using semistructured questioners by interview and the obtained data was analysed using SPSS v.24.0 statistical software. Statistical significance was declared at P-value of 0.25 for bivariate and 0.05 for multivariable logistic regressions.

Results: On this study $53 \%$ of mothers were found to have poor knowledge and $42.6 \%$ of mothers had poor attitude. This study also found educational status of mothers; occupational status and adequate counselling and education from health professionals are associated with knowledge on growth monitoring. Poor knowledge and adequate counselling and education from health professionals were significantly associated with attitude towards growth monitoring.

Conclusion and Recommendation: Mothers have relatively good attitude than knowledge. Formal education, counselling and education from health professionals and a formal occupation had a positive impact on knowledge and attitude towards growth monitoring. The knowledge status of the mothers was found to be low.
\end{abstract}

Keywords: Growth monitoring; Knowledge; Attitude

Abbreviation: AOR: Adjusted Odds Ratio; CBGP: Community Based growth Promotion; CI: Confidence Interval; COR: Crude Odds Ratio; ETB: Ethiopian Birr; FGD: Focus Group Discussions; GC: Growth Chart; GM: Growth Monitoring; GMP: Growth Monitoring Practice; Hews: Health Extension Workers; IDD: Iodine Deficiency Disorders; KAP: Knowledge, Attitude and Practice; NGO: Non-Governmental Organizations; OR: Odd Ratio; SNNPR: Southern Nations Nationalities and People Region; WHO: World Health Organization; VCHW: Voluntary Community Health Workers

\section{Introduction}

Growth monitoring is a process of regular weighing (and measuring height in some cases) and comparing the results with a standard, is used in numerous community-based program settings to assess the growth status of children and often also to determine whether to deliver additional interventions $[1,2]$. The major merit of GM is, its use as a diagnostic tool for identifying a child with a nutritional or health problem, thus enabling action to be taken before the child's nutritional status is seriously endangered [3].

Severe acute malnutrition affects nearly 20 million preschool-age children, mostly from African and South-East Asia Region. According to a recent data, of the 7.6 million deaths annually among children who are under 5 years of age, approximately $35 \%$ are due to nutritionrelated factors and $4.4 \%$ of the deaths have been shown to be specifically attributable to severe wasting [4].

Another term, Growth Monitoring and Promotion (GMP) is a preventive activity comprised of GM linked usually with counselling that increases awareness about child growth; improves caring practices and increases demand for other services [1]. GM is the central starting point for GMP; the monitoring must occur regularly and be focused on growth status (the velocity of growth), not on anthropometric status. GMP links the information gathered over time from GM with an action as monitoring child growth alone will not result in changes in growth [1].

The rationale for monitoring the growth of a child most commonly done in the developing world through monitoring weight, but can include monitoring length/height is based on the assumptions that growth is a good proxy for overall child well-being and its measurement serves as a robust indicator. The other assumption is, growth is a dynamic process that is made visible by monitoring changes in anthropometric indices and reflects current, not past, events [1].

GM is frequent and routine that, it requires strict adherence and families need to bring their children every month till at least 2 years of age [5-7]. And for the growth monitoring programs to be effective mothers should have adequate knowledge, positive attitude and good

*Corresponding author: Tomas Yeheyis, Department of Nursing, College of Medicine and Health Science, Arba Minch University, Ethiopia. Tel: +251913003505; E-mail: tyeheyis@gmail.com

Received July 19, 2017; Accepted August 03, 2017; Published August 10, 2017

Citation: Daniel B, Tesfaye N, Mekonin E, Kassa A, Mensur K, et al. (2017) Knowledge and Attitude on Growth Monitoring and its Associated Factors among Mothers/Guardians of Children Less than Two Years in Areka Town, Southern Ethiopia, 2017. J Nutr Disorders Ther 7: 216. doi: 10.4172/21610509.1000216

Copyright: ( 2017 Daniel B, et al. This is an open-access article distributed unde the terms of the Creative Commons Attribution License, which permits unrestricted use, distribution, and reproduction in any medium, provided the original author and source are credited. 
Citation: Daniel B, Tesfaye N, Mekonin E, Kassa A, Mensur K, et al. (2017) Knowledge and Attitude on Growth Monitoring and its Associated Factors among Mothers/Guardians of Children Less than Two Years in Areka Town, Southern Ethiopia, 2017. J Nutr Disorders Ther 7: 216. doi: 10.4172/2161- 0509.1000216

Page 2 of 6

practice. However, this maternal attribute are being stated in many studies as one of the impending factors for the effectiveness of growth monitoring. Mothers who neglect to bring their children for growth monitoring were the main reasons for the poor implementation of growth monitoring in different areas. One of the reasons which convinced mothers that GM has no benefit is because they don't see any interventions being carried out during the visits except for weighing the child and said parents don't believe that weighing a child could bring any change to their growth [8].

Recently questions have been raised about whether growth monitoring is not being implemented as it was intended to be. The most dominating factor being indicated behind this poor implementation was poor adherence of mothers to the growth monitoring programs and this could be highly determined by their understanding and perception toward growth monitoring [2]. An anecdotal observation of the research group members in different health institutions in our country also indicates that, even though growth monitoring is and has been considered as a sole preventing and screening mechanism by the Federal Ministry of Health of Ethiopia, its implementation in practical level is disappointing. Several factors can be considered as contributing to this poor practice, including poor understanding and motivation of health care workers, poor maternal knowledge, attitude and practice as well as lack of available resource. In this study, our major concern is the maternal KAP on the growth monitoring programs.

Parents, especially mothers, have an irreplaceable role in ensuring continued follow up and strict adherence to the growth monitoring schedules. This role of mothers should be clearly studied in relation to different parameters including their knowledge and attitude.

Studying these parameters will help to identify the associated factors behind growth monitoring which can lead to better utilization of it. Children will better have their growth monitored regularly and help them to be benefited from the intended advantages of growth monitoring. Parents and also the community at large will be benefited from the resulting reduction and prevention of malnutrition and its widespread, everlasting effect.

\section{Materials and Methods}

\section{Study setting, design and period}

The study is conducted in Areka town, which is of the city administrations of Wolayta zone with a distance of $29 \mathrm{~km}$ from the zonal capital Wolita Sodo and $183 \mathrm{~km}$ from, Hawassa, a capital city of SNNPR and $300 \mathrm{~km}$ from Addis Ababa, country capital. Areka has total population of 59,411 from which 29,884 are males and 29, 527 are females [9]. This study was carried out using Community based quantitative cross-sectional study design from June 2 to June 12, 2017.

Total sample size was determined using single population proportion formula with 95\% confidence interval (CI) and marginal error (d) of $5 \%$.

$$
n=\frac{\left(z_{\frac{\alpha}{2}}\right)^{2} p(1-p)}{d^{2}}
$$

Where $\quad \mathrm{n}=$ The desired sample size

$$
\mathrm{Z}=\text { Standard normal score }(95 \%)
$$

$\mathrm{d}=$ Margin of error $(5 \%)$
$\mathrm{P}=53 \%$, from the mothers having good knowledge taken from the study conducted in Ghana

$$
z_{\frac{\alpha}{2}}=1.96 \quad\left(z_{\frac{\alpha}{2}}\right)^{2}=3.84
$$

$\mathrm{n}=382$

When we add $10 \%$ non-response rate the total sample size became $420.2 \approx 420$.

Then using population correction formula, we calculated the sample size for finite population taking the town's total under two years of age children which is 3078 .

$$
n=\left(\frac{n i}{1+\frac{n i}{N}}\right)
$$

The final sample size then became 369 .

Areka town has four kebles and in this study. Proportional sample size allocation was used to distribute the total sample size into the four Kebeles, then systematic random sampling was used to select individual households to reach study subject: primarily the mother/guardian of a child less than 2 years of age.

\section{Instrument and data collection technique}

Semi-structured questioner was prepared in Amharic by reviewing different literatures and was used for face to face interviews. Group members conducted the interviews using pen, pencils and papers. Before data collection, a brief discussion was made with data collectors to have a common understanding. We have obtained the list of mothers with children less than 2 years of age and their house numbers from the health extension workers of each Kebele and used it as a sample frame. Then the house numbers were recorded and selected the house holds using systematic random sampling with $\mathrm{K}^{\text {th }}$ interval of 8 . One health extension workers from each kebele was assigned and linked data collectors with health development army leaders in each ketenas. Data from one kebele were collected on one day and one additional day for revisits totally 5 days.

Based on the instrument used poor attitude was implied when mothers are responding to the attitude questions with the score of 0-2. Good attitude: when mothers are responding to the attitude questions with the score of 3-5. poor knowledge: Those mothers who score 0-7 for the knowledge questions, good knowledge. Those who score 8-6 for the knowledge questions.

\section{Data analysis}

After the data was collected, questionnaires were reviewed and organized by investigators. The data were entered after defining variables and analysed using SPSS v. 24.0 statistical software. Binary Logistic regression was performed. COR (crude odds ratio) along with $95 \%$ confidence interval was used to determine the existence of an association between independent and dependent variables. Then multivariate logistic regression was used to decrease the effect of confounding factors. Statistical significance was declared with p-value less than 0.05 for multivariable and 0.25 for bivariate logistic regressions. Finally, the result is presented using tables, texts and other pictorial representation.

\section{Data quality control}

The questionnaire was taken from similar studies [10-12] and was modified to adapt to the study context. Before the data collection, the data collectors made sure that they have a common understanding of 
Citation: Daniel B, Tesfaye N, Mekonin E, Kassa A, Mensur K, et al. (2017) Knowledge and Attitude on Growth Monitoring and its Associated Factors among Mothers/Guardians of Children Less than Two Years in Areka Town, Southern Ethiopia, 2017. J Nutr Disorders Ther 7: 216. doi: 10.4172/2161- 0509.1000216

Page 3 of 6

the questionnaire and the questionnaire was translated to Amharic and back to English. After data collection, internal consistency was checked by cross checking the collected data within on every day of data collection. If proper respondents were not available on the first visit, one additional visit was considered before taking as a non-response.

\section{Ethical consideration}

Before the data collection, letter of support to conduct the study was obtained from Arbaminch University, College of medicine and health Sciences, Department of nursing. The respondent's privacy and confidentiality of the information was assured throughout the study procedure, and they had all the right not to involve in the study or not to answer any of the questions. The research team ensured that any data was collected after taking full verbal consent of participants.

\section{Results}

\section{Socio demographic characters}

From the total sample size of 369,336 mothers were interviewed making the response rate of $91 \%$. From total of 336 mothers who responded in our study, the mean age was 28.8 ( $\mathrm{SD} \pm 6.51$ ). Majority (33.9\%) of mothers who responded in this study have attended primary education and $28 \%$ of mothers can't read and write. Around 57\% (192) mothers have 3 and more children and 42.9\% (144) mothers have 1-2 children. $54.8 \%$ (184) mothers have child whose age is 1 years to 2 years and the rest $45.2 \%$ (152) have a child less than 1 year of age. And Among these children, $48.5 \%$ (163) are male and 51.5\% (173) are female.

The Table 1 above shows the socio demographic characters of mothers of children less than 2 years of age including religion, ethnicity, educational status and occupation.

\section{Knowledge on GM}

This study has identified that, majority $(36.9 \%)$ of mothers think GM is provided for under five children. $31.8 \%$ of mothers participated in this study don't know when the growth monitoring service is started. Most of the respondents (32.1\%) responded that, GM service is provided every month. Nurses (37.5) and HEWs (36.9) were most commonly stated to provide the GM services. Large majority (70.2\%) of mothers said GM service is provided at health centres.

When asked about the definition of the growth chart $44(13.1 \%)$ said it is a tool that shows the health status of the child, $94(28.0 \%)$ said a tool that shows developmental status of children, 46 (13.7\%) of them think it is a certificate which is given for completing immunization and 152 (45.2\%) of mothers said they don't know the definition of growth charts. From the total, 190 (56.5\%) of mothers said their children have GC and among those which have growth chart, 37.9\% of them don't know what the curves mean.

The Table 2 above clearly shows respondents responses on knowledge related questions of the study.

\section{Attitude of mothers toward GM}

Regarding the attitude of mothers toward GM, 308 (91.7\%) of mothers believe that GM is important and among those who believe it is important, $192(62.3 \%)$ of them think it is important to prevent disease.

From total of 336 mothers, 212 of the mothers expressed their feelings to bring their child to the GM visits. From those, 192 (90.6\%) of them are happy and the rest $20(9.4 \%)$ are not happy to bring their

\begin{tabular}{|c|c|c|c|}
\hline \multicolumn{2}{|c|}{ Variables } & \multirow{2}{*}{ Frequency } & \multirow{2}{*}{ Percent } \\
\hline Variable name & Category & & \\
\hline \multirow{8}{*}{ Age of mothers } & $15-19$ & 16 & 4.8 \\
\hline & $20-24$ & 74 & 22 \\
\hline & $25-29$ & 117 & 34.8 \\
\hline & $30-34$ & 68 & 20.2 \\
\hline & $35-39$ & 41 & 12.2 \\
\hline & $40-44$ & 12 & 3.6 \\
\hline & $45-49$ & 6 & - \\
\hline & $>49$ & 2 & - \\
\hline \multirow{5}{*}{ Religion of mothers } & Orthodox & 113 & 33.6 \\
\hline & Muslim & 47 & 14 \\
\hline & Catholic & 23 & 6.8 \\
\hline & Protestant & 141 & 42 \\
\hline & Other & 12 & 3.6 \\
\hline \multirow{4}{*}{ Ethnicity of mothers } & Wolayita & 230 & 68.5 \\
\hline & Gurage & 42 & 12.5 \\
\hline & Kembata & 30 & 8.9 \\
\hline & Other & 34 & 10.1 \\
\hline \multirow{5}{*}{$\begin{array}{l}\text { Educational status of } \\
\text { mothers }\end{array}$} & Can't Read and write & 94 & 28 \\
\hline & Primary Education & 114 & 33.9 \\
\hline & Secondary Education & 54 & 16.1 \\
\hline & Beyond secondary & 62 & 18.5 \\
\hline & Other & 12 & 3.6 \\
\hline \multirow{5}{*}{$\begin{array}{l}\text { Occupational status of } \\
\text { mothers }\end{array}$} & Employee (Gov't or NGO) & 72 & 21.4 \\
\hline & Self employed & 92 & 27.4 \\
\hline & No occupation & 116 & 34.5 \\
\hline & Farmer & 24 & 7.1 \\
\hline & Informal occupation & 32 & 9.5 \\
\hline \multirow{6}{*}{$\begin{array}{l}\text { Occupational status of } \\
\text { partners (marital) }\end{array}$} & Employee (Gov't or NGO) & 99 & 29.5 \\
\hline & Self employed & 105 & 31.8 \\
\hline & No occupation & 16 & 4.8 \\
\hline & Farmer & 50 & 14.9 \\
\hline & Informal occupation & 28 & 8.3 \\
\hline & Not married & 36 & 10.7 \\
\hline \multirow{4}{*}{ Marital Status } & Single & 5 & - \\
\hline & Married & 300 & 89.3 \\
\hline & Divorced & 19 & 5.7 \\
\hline & Widowed & 12 & 3.6 \\
\hline \multirow{4}{*}{$\begin{array}{l}\text { Estimated amount of } \\
\text { average family monthly } \\
\text { income }\end{array}$} & Less than 500 Birr & 28 & 8.3 \\
\hline & 500 to 1000 Birr & 118 & 35.1 \\
\hline & 1000 to 2000 Birr & 115 & 34.2 \\
\hline & Above 2000 Birr & 75 & 22.3 \\
\hline
\end{tabular}

Table 1: Socio demographic and economic characteristics of study participants, in Areka town, Ethiopia, 2017.

children to GM visits. According to the results, 143 (42.6\%) of the mothers have poor attitude and 193 (57.4\%) of the mothers have good attitude.

\section{Factors associated with poor knowledge about growth monitoring}

On this study, bivariate logistic regression analysis revealed significant association between knowledge on GM and educational status of mothers, occupational status and adequate counselling and education from health professionals. Mothers who have no formal education were 1.992 times more likely to have poor knowledge in GM (AOR 1.992(95\% CI, 1.230-3.225)). Mothers with no formal occupation were 1.680 times more likely to have poor knowledge on GM (AOR 1.680 (95\% CI, 1.079-2.614)). Mothers who said they don't get adequate 
Citation: Daniel B, Tesfaye N, Mekonin E, Kassa A, Mensur K, et al. (2017) Knowledge and Attitude on Growth Monitoring and its Associated Factors among Mothers/Guardians of Children Less than Two Years in Areka Town, Southern Ethiopia, 2017. J Nutr Disorders Ther 7: 216. doi: 10.4172/2161- 0509.1000216

Page 4 of 6

\begin{tabular}{|c|c|c|c|c|c|}
\hline Variable & \multicolumn{3}{|c|}{ Category } & Frequency & Percent \\
\hline \multirow{6}{*}{ Knowledge on the definition of GM } & \multirow{3}{*}{ Yes } & \multicolumn{2}{|c|}{ Following the growth of the child } & 59 & 17.6 \\
\hline & & \multicolumn{2}{|c|}{ Is a program to screen children which have malnutrition } & 26 & 7.7 \\
\hline & & \multicolumn{2}{|c|}{ Is taking care of children's nutrition and hygiene } & 46 & 13.7 \\
\hline & \multicolumn{3}{|c|}{ Other } & 10 & - \\
\hline & \multicolumn{3}{|c|}{ Total } & 141 & 42 \\
\hline & \multicolumn{3}{|c|}{ No } & 195 & 58 \\
\hline \multirow{5}{*}{ Eligible groups for GM } & \multicolumn{3}{|c|}{ Children $<2$ years of age } & 66 & 19.6 \\
\hline & \multicolumn{3}{|c|}{ Children 0 years to 5 years of age } & 124 & 36.9 \\
\hline & \multicolumn{3}{|c|}{ Those children whose parents are poor } & 22 & 6.5 \\
\hline & \multicolumn{3}{|c|}{ Sick children } & 20 & 6 \\
\hline & \multicolumn{3}{|c|}{ Don't know } & 104 & 31 \\
\hline \multirow{5}{*}{ Starting time for GM } & \multicolumn{3}{|c|}{ At birth } & 109 & 32.4 \\
\hline & \multicolumn{3}{|c|}{ At 1 month of age } & 78 & 23.2 \\
\hline & \multicolumn{3}{|c|}{ At age of 1 year } & 24 & 7.1 \\
\hline & \multicolumn{3}{|c|}{ After 2 years of age } & 18 & 5.4 \\
\hline & & Don & & 107 & 31.8 \\
\hline & & Ever & & 18 & 5.4 \\
\hline & & Ever & & 108 & 32.1 \\
\hline Interval Between GM visits & & Ever & & 36 & 10.7 \\
\hline & & Every & & 70 & 20.8 \\
\hline & & Don & & 104 & 31 \\
\hline & & & & 124 & 36.9 \\
\hline & & & & 126 & 37.5 \\
\hline GM service providers & & Mid & & 44 & 13.1 \\
\hline & & & & 36 & 10.7 \\
\hline & & Tea & & 6 & - \\
\hline & & Heal & & 36 & 10.7 \\
\hline & & Healt & & 236 & 70.2 \\
\hline Place of GM service provision & & & & 26 & 7.7 \\
\hline & & & & 8 & - \\
\hline & & Home & & 30 & 8.9 \\
\hline & & unc & & & \\
\hline & Have & They sh & & 18 & 5.4 \\
\hline & growth & They show & & 74 & 22 \\
\hline & & The & & 26 & 7.7 \\
\hline Possession of Grouth chart & & & & 72 & 21.4 \\
\hline 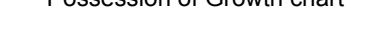 & & Reason for $n$ & hart & - & - \\
\hline & & & & 6 & - \\
\hline & Don't have & I didn' & & 18 & 5.4 \\
\hline & & & & 11 & 3.3 \\
\hline & & & & 111 & 33 \\
\hline & & llness & YYes & 240 & 71.4 \\
\hline & & IIIness & No & 96 & 28.6 \\
\hline & & Reath & Yes & 104 & 31 \\
\hline & & Lediu! & No & 232 & 69 \\
\hline Imnacts of malnutrition & & Revelonmental delav & Yes & 106 & 31.5 \\
\hline - & & Leveropinemiar meray & No & 230 & 68.5 \\
\hline & & No imnact & Yes & 8 & - \\
\hline & & INU impact & No & 328 & 97.6 \\
\hline & & Don't know & Yes & 24 & 7.1 \\
\hline & & DOmL knOW & No & 312 & 92.9 \\
\hline
\end{tabular}

Table 2: Knowledge of mothers on different aspects of growth monitoring, in Areka town, Ethiopia, 2017.

counselling and education about GM from health professionals were 1.779 times more likely to have poor knowledge (AOR 1.799 (95\% CI, $1.129-2.804))$.

Bivariate and multivariate logistic regression has been applied to see the association between knowledge of mothers and independent variables like educational status, occupation and adequate counselling in Table 3.

Factors associated with poor attitude about growth monitoring

On this study, bivariate logistic regression revealed significant 
Citation: Daniel B, Tesfaye N, Mekonin E, Kassa A, Mensur K, et al. (2017) Knowledge and Attitude on Growth Monitoring and its Associated Factors among Mothers/Guardians of Children Less than Two Years in Areka Town, Southern Ethiopia, 2017. J Nutr Disorders Ther 7: 216. doi: 10.4172/2161- 0509.1000216

Page 5 of 6

\begin{tabular}{|c|c|c|c|c|c|c|}
\hline \multicolumn{2}{|c|}{ Independent variables } & Good knowledge n(\%) & Poor knowledge n(\%) & COR(95\%Cl) & P-value & AOR(95\%Cl) \\
\hline \multirow{2}{*}{ Educational status of mothers } & Educated & $120(52.4)$ & $109(47.6)$ & 1 & 1 \\
\cline { 2 - 7 } & No formal education & $38(35.5 \%)$ & $69(64.5 \%)$ & $1.999(1.245-3.209)$ & 0.004 & $1.992(1.230-3.225)$ \\
\hline \multirow{2}{*}{ Occupational status of mothers } & Formal occupation & $88(53.0)$ & $78(46.9)$ & 1 & 1 \\
\cline { 2 - 7 } & No formal occupation & $70(41.1)$ & $100(58.9)$ & $1.612(1.047-2.481)$ & 0.03 & $1.680(1.079-2.614)$ \\
\hline \multirow{2}{*}{ Adequate counseling } & Yes & $122(58.1)$ & $88(41.9)$ & 1 & 1 \\
\cline { 2 - 7 } & No & $36(28.6)$ & $90(71.4)$ & $1.792(1.148-2.797)$ & 0.01 & $1.779(1.129-2.804)$ \\
\hline
\end{tabular}

Table 3: Association between Independent variables and Knowledge of mothers on growth monitoring in Areka town, Ethiopia, 2017.

\begin{tabular}{|c|c|c|c|c|c|c|}
\hline \multicolumn{2}{|c|}{ Independent variables } & Good Attitude n(\%) & Poor attitude $n(\%)$ & $\operatorname{COR}(95 \% \mathrm{Cl})$ & P-value & AOR(95\%Cl) \\
\hline \multirow{2}{*}{ Educational status } & Formal education & $138(60.2)$ & $91(39.8)$ & 1 & & \\
\hline & No formal education & $55(51.4)$ & $52(48.6)$ & $1.434(0.903-0.277)$ & 0.127 & \\
\hline \multirow{2}{*}{ Sex of the last child } & Male & $101(61.9)$ & $62(38.1)$ & 1 & & \\
\hline & Female & $92(53.2)$ & $81(46.8)$ & $1.434(0.928-2.216)$ & 0.104 & \\
\hline \multirow{2}{*}{$\begin{array}{l}\text { Estimated amount of average monthly } \\
\text { family income }\end{array}$} & $>500$ ETB & $181(58.7)$ & $127(41.3)$ & 1 & & \\
\hline & $<=500$ ETB & $12(42.9)$ & $16(57.1)$ & $1.900(0.869-4.154)$ & 0.108 & \\
\hline \multirow{2}{*}{$\begin{array}{l}\text { Adequate counseling and Education } \\
\text { from health professionals }\end{array}$} & Yes & $135(66.5)$ & $68(33.5)$ & 1 & & 1 \\
\hline & No & $58(43.6)$ & $75(56.4)$ & $2.567(1.637-4.026)$ & 0 & $1.994(1.224-3.248)$ \\
\hline \multirow{2}{*}{ Knowledge status } & Good knowledge & $108(68.3)$ & $50(31.7)$ & 1 & & 1 \\
\hline & Poor Knowledge & $85(47.8)$ & $93(52.2)$ & $2.363(1.513-3.692)$ & 0.000 & $2.039(1.273-3.263)$ \\
\hline
\end{tabular}

Table 4: Factors associated with poor attitude of mothers on GM in Areka town, SNNPR, Ethiopia, 2017.

association between Attitude on GM and educational status (COR $1.434(\mathrm{p}=0.127))$, sex of the last child (COR $1.434(\mathrm{p}=0.104))$, Estimated amount of average monthly family income (COR 1.900(0.108)), adequate counselling and education from health professionals (COR $2.567(\mathrm{p}=0.000)$ ), knowledge status (COR $2.363(\mathrm{p}=0.000))$. To further examine the association, variables that were found to have association with poor attitude towards GM from bivariate analysis were alone explored, and only the two variables were confirmed to have association. Mothers who have poor knowledge were 2.039 times more likely to have poor attitude toward GM than those with good knowledge (AOR 2.039 (95\% CI, 1.273-3.263)) and those mothers who claimed to get adequate counselling and education from health professionals were found to be 1.994 times more likely to have poor attitude toward GM than who said they don't (AOR 1.994 (95\% CI, 1.224-3.248)). Attitude of mothers and independent variables show an association in multivariate logistic regression in table 4 .

\section{Discussion}

When asked about the definition of the growth chart, $28.0 \%$ of mothers responded that it is a tool that shows developmental status of children, and $45.2 \%$ of mothers said they don't know the definition of growth charts. This finding is consistent with many of other studies which assessed the comprehension of growth chart by mothers. On the review documents prepared on GM, less than $25 \%$ of the mothers were found to be knowledgeable about the definition of growth charts [7]. Regarding the interpretation of the growth chart, on this study, $37.9 \%$ don't know what the curves mean. This finding is better when compared to the study conducted in Saudi Arabia which indicated that $42.1 \%$ of mothers don't know the correct interpretation of growth charts. The difference may come from the time difference between the two studies as awareness can be generally increased and the GCs have been improved and simplified since then.

On this study, regarding the knowledge of mothers about the difference between GM and immunization, $44 \%$ mothers said they are the same and the rest $56 \%$ of the mothers said they are separate. This perceived similarity between immunization and GM was also observed in other studies such as the Ethiopian study conducted in Tigry region $[13,14]$. The overall knowledge status found in this study indicates that, $53 \%$ of the mothers have poor knowledge. This is lower than similar study conducted in Ghana. Even though the indicated poor knowledge status on that study was $53 \%$ which is, the Ghanaian study used 3 levels of scoring and the next majority of the mothers in that study had moderate knowledge which in this study might be included under poor knowledge.

On this study, $91.7 \%$ of respondents participated in this study said GM is important and $89.9 \%$ of them think GM can contribute to the growth of their child. This finding is consistent with similar study conducted in Ghana which is $93.7 \%$ [12]. The stated importance, that the mothers responded in this study given were, to prevent disease and to obtain food aid. These findings were also observed in the study in Tigry region. These observed similarities might come from the close socio-cultural proximity of the two communities. The perception is that, GM is for screening children for food aid was one of the attitudes observed both in this study and Tigry study. In addition to this, food support (30.7\%) and money support (28.9\%) were activities indicated by study participants to be added to the GM activities. This further indicates that GM is perceived to be linked with nutritional and financial aids and this perceived linkage was also indicated in the Ethiopian [14] and South African [15,16] studies as the main reason for the mothers to default from the GM program because they are not getting the direct economic benefits they expected at first. This study identified that around 57.4\% mothers have good attitude toward GM service which is significantly lower than the study in Ghana 98.0\% [11]. The observed difference from the Ghanaian study might be attributed to the poor implantation of the program in the study area and also the fact that, practically health education activities are not incorporated sufficiently to the GM programs in Ethiopia.

Similar to the study in upper west region of Ghana, this study has identified significant association of educational status (AOR 1.992(95\% CI, 1.230-3.225)) and occupational status (AOR 1.680 (95\% CI, 1.0792.614)) with knowledge of mothers. In addition, mothers who said they don't get adequate counselling and education were found to be 1.779 times more likely to have poor knowledge on GM than those who get 
Citation: Daniel B, Tesfaye N, Mekonin E, Kassa A, Mensur K, et al. (2017) Knowledge and Attitude on Growth Monitoring and its Associated Factors among Mothers/Guardians of Children Less than Two Years in Areka Town, Southern Ethiopia, 2017. J Nutr Disorders Ther 7: 216. doi: 10.4172/2161- 0509.1000216

Page 6 of 6

counselling (AOR 1.799 (95\% CI, 1.129-2.804)). This association was also indicated on the study conducted in South Africa even though; statistical significance was not tasted due to the methodology of the study which used panels and FGDs.

Significant association was also revealed on this study between poor attitude of mothers and the knowledge status (AOR $2.039(95 \%$ CI, 1.273-3.263)) as well as adequate counselling and education (AOR 1.994 (95\% CI, 1.224-3.248)). It is predictable that mothers which got adequate counselling and knowledge can have relatively good attitude toward GM than who don't and also most non-educated mothers are likely to perceive nearly every activity performed by health professionals as important to their child even though they don't know about it.

\section{Conclusion}

GM program is currently being considered as similar with immunization activity and also others consider it as a screening program for malnutrition and food aid instead of separate regular, continuous and sustainable growth monitoring and promotion program. The overall knowledge and attitude status of mothers in the town was found to be relatively low.

Mothers which have no education, no formal education and those who don't get adequate counselling were more likely to have poor knowledge. Mothers who don't get adequate counselling and those which have poor knowledge were more likely to have poor attitude and mothers who had Poor knowledge and attitude.

\section{Acknowledgment}

We would also like to thank all the staffs of Areka town health unit, disease prevention and health promotion work process and the manager of Areka health center, All the health extension workers of Areka town and their coordinator Mr. Mengistu for their cooperation in providing the information's we requested and guiding the data collectors throughout the data collection days. Administrators of all 4 kebeles in the town, all the HDA leaders in all ketenas of the town and all respondents of our study. Finally, our thanks shall go to all those who contributed to the completion of this proposal in one way or another.

\section{References}

1. Griffiths M, Rosso JD (2007) Growth monitoring and the promotion of healthy young child growth: Evidence of effectiveness and potential to prevent malnutrition. The Manoff Group.

2. Nuné M, Mandana A, Werner S (2011) Revisiting the concept of growth monitoring and its possible role in community-based nutrition programs. Food Nutr Bull 32: 42-53.

3. Ann A, Roger S, Kazi J (2008) Growth monitoring and promotion: Review of evidence of impact. Matern Child Nutr 4: 86-117

4. WHO, Guideline: (2013) Updates on the management of severe acute malnutrition in infants and children, Geneva: World Health Organization, Switzerland.

5. WHO, Nutrition and HIVIAIDS: A training manual for nurses and midwives World Health organization, Geneva, Switzerland.

6. FMOH (2007) Protocol for the management of severe acute malnutrition, Ethiopia-Federal Ministry of Health, Addis Ababa, Ethiopia.

7. Roberfroid D, Pelto GH, Kolsteren P (2007) Plot and see! Maternal comprehension of growth charts worldwide. Trop Med Int Health 12: 1074-1086.

8. Dominique R, Pierre L, Tom H, Patrick K (2005) Perceptions of growth monitoring and promotion among an International Panel of District Medical Officers. J Health Popul Nutr 23: 207-214.

9. https://en.wikipedia.org/wiki/Areka

10. Shams B, Golshiri P, Zamani AR, Pourabdian S (2008) Mothers' participation in improving growth and nutrition of the children: A model for community participation. Iranian J Public Health 37: 24.

11. Parveen R, Tamara JS, Buthina EA, Aida M (1995) The growth chart-its use and perception among mothers visiting primary health care centers of Al-khobar Saudi Arabia. Saudi Med J 17: 195-204.

12. Debora TD, Prince KA, Margaret K, et al. (2017) Caregivers knowledge, attitude and practices on child growth monitoring and promotion activities in Lawra District, Upper West Region of Ghana. Sci J Public Health 5: 20-30.

13. Nombe $E$ (1992) Investigation in to the knowledge mothers have about children's growth charts. Curationis 15: 26-28.

14. Selamawit MB, Albine M, Roman B (2014) Practices and challenges of growth monitoring and promotion in Ethiopia: A qualitative study. J Health Popul Nutr 32: $441-451$.

15. Abdurrahman M, Nahed A (2001) Maternal comprehension of home-based growth chart in Bahrain. Trop Doct 31:161-165.

16. Mieke F, Michael A, Jane D (2003) Acceptability of community-based growth monitoring in a rural village in South Africa. Food Nutr Bull 24: 350-359. 